\title{
THE CHANGING STATUS OF THE GERMAN COCKROACH IN THE URBAN ENVIRONMENT
}

\author{
W.H. ROBINSON \\ Urban Pest Control Research Center, 610 North Main Street, \\ \#176, Blacksburg, VA 24060 USA
}

\begin{abstract}
The abundance and pest status of the German cockroach, Blattella germanica (L.), has been declining worldwide. This once dominant household pest has been displaced from domestic habitats as a result of a combination of factors and changes in the urban environment, including general improvements in building construction, which resulted in decreased movement of cockroaches in buildings; crack and crevice application of insecticides removed harborages; pyrethroid insecticides and bait formulations significantly reduced populations to the point, the tipping point, from which they could not recover. The implications of this change in the dominance of the German cockroach include the emergence of ants as an important pest, and the increased utility of baits for the control of household and structural insect pests.
\end{abstract}

Keywords: Blattella germanica, pest status, control, population reservoir.

\section{INTRODUCTION}

After decades of abundance and pest dominance in households around the world the reign of the German cockroach, Blattella germanica (L.), is coming to an end. The presence of this cockroach in residential and commercial sites in the urban environment has been declining for several years, and in many areas it is no longer considered an economically important pest (Rasmussen and Nielsen 1997; Landau et al. 1999). Considering the long history and wide distribution of the cockroach that virtually defined the term household pest in modern society, prospect of it loosing pest status seems doubtful - at best. However, evidence of the change, coupled with a decrease in the use of cockroach control materials, have been emerging for the last ten years in Asia, Europe, and North America. It is not merely a temporary setback for this pestscience and society have conspired to make it permanent.

The reasons and the timetable of this change are becoming clear. The decline of B. germanica has been gradual, and not associated with a single event, an insecticide, or a dramatic change in the urban environment. The German cockroach is a highly adaptable insect, with a history and a folklore of surviving the most sophisticated insecticides and a thermonuclear explosion (Cole et al. 1959). Dislodging it from the household environment was achieved through a unique combination of procedures and products that came together in the last ten years. These include general improvements in building construction, the chemical application methods of professional pest control operators and some specific control materials available to homemakers and professionals. Separately, these features may not have had the influence they had in combination and in sequence.

This change is an important development in the urban environment and for the study of invertebrate and vertebrates pests in this environment. A review of the causes and effects of this development can be useful. The ultimate consequences of a change in the hierarchy of household pests are not known, yet early indications do not appear to be all good. One side effect seems to be an increase in the presence of ants, silverfish, stored-food insects, and other secondary household pests. The specific objectives of this paper are to present the sequence of events that brought about the decline in

Proc. 52nd N.Z. Plant Protection Conf. 1999: 16-21 
German cockroach abundance, discuss why a reversal of this trend is not likely, and review the implications all this has on some other pests in the urban environment.

\section{DECLINE IN GERMAN COCKROACH POPULATIONS}

The German cockroach became a common and economically important household pest in most of the developed countries of the world within the last century. It was during this time household features such as indoor plumbing, central heating, and food storage became common in nearly all socioeconomic levels. Before that few households provided the habitats and conditions suitable for this tropical insect to survive year round (Zhai 1990; Steyskal and Verner 1996). Equally important is the fact that before the availability of these features there were few locations, (such as grocery stores and warehouses) in the urban environment that could sustain large cockroach populations, and serve as source for infesting other sites. Improvements in the living space that provided food, water, and a heated harborage positioned this insect to take advantage of the habitats and habits of modern society. B. germanica rose to the challenge and quickly became the number one household insect pest.

\section{Household environment}

In general, construction methods and materials for urban buildings have improved in the last three decades. The expansion of the suburban rings of major metropolitan areas around the world has lead to tracts of large apartment buildings. The very nature of buildings, with multiple units and a range of living and housekeeping habits, provides potential for cockroach infestation. However, in recent years these buildings have benefited from improved construction in kitchens and bathrooms which have removed or limited habitats for $B$. germanica. The most important aspect of improved construction on cockroach infestations is limiting the movement of cockroaches between units. Field studies in urban apartment buildings confirmed that adults and nymphs move within and between apartments (Zungoli 1982; Runstrum and Bennett 1984), and attempts to limit this movement by caulking or other post-construction practices are difficult and not effective (Farmer and Robinson 1984).

Harborage within dwelling units has probably changed little with improved construction practices. If anything, it may have increased with modern kitchen and bathroom cabinetry and appliances. These structural features provide $B$. germanica an abundance of $6.3 \mathrm{~mm}$ - to $12.7 \mathrm{~mm}$-wide spaces preferred by adults and nymphs (Koehler et al. 1994). Reducing the availability of this harborage by caulking or other means seems a logical component of a cockroach control program. However, the utility of caulking does not mean that it is effective, and it is not. About $45 \%$ of the cracks and crevices in kitchen cabinets are accessible to caulking, the remainder are difficult to reach with either caulking or liquid sprays (Farmer and Robinson 1984). As application methods evolved from surface sprays to crack and crevice treatment, the apparent utility of caulking has diminished.

\section{Insecticide application}

The lucrative household pest control market provided impetus to find the most effective cockroach control material (USDA, 1989). Although the 'silver bullet' for cockroach control was not found, some unique control materials and application methods were developed to effectively reduce household infestations of $B$. germanica. For many years cockroach control was based on spraying liquid insecticides onto baseboards and other exposed surfaces. The objective was to leave a residue where cockroaches would walk during their search for food and water. The most common victims of this application method were male cockroaches foraging away from harborage sites. Gravid females and small nymphs usually remain within or close to harborages, and were less likely to contact these residues. Thus, monthly applications would usually kill males, and infestations were easily sustained by the remaining females and nymphs.

The concept of applying insecticides to cockroach-infested cracks and crevices became a feature of professional service and home-use products in the 1970s. This was a significant development in German cockroach control, because the emphasis was on placing insecticide into harborages used by $B$. germanica. Residual insecticides in 
infested harborages decreased the opportunity for cockroaches to avoid treated surfaces when dispersing. Crack and crevice application soon became the accepted standard for cockroach control - and spraying baseboards something done by the unenlightened. The concept of identifying and treating infested harborages would, in a sense, pre-condition pest control service technicians for the next major change in cockroach control, the use of baits.

\section{Insecticides}

Until the 1980s, when pyrethroids became available for household pest control, the dominant classes of insecticides were organophosphates and carbamates. Residues of these compounds provided consistent control of German cockroaches, even in the face of the physiological resistance that developed in many field populations (Rust and Reierson 1991). The introduction of pyrethroid insecticides, such as cypermethrin, cyfluthrin, and deltamethrin significantly improved cockroach control. These compounds are essentially odorless, applied at low $(0.1,0.2 \%)$ concentrations, and they provide an almost immediate flushing action, followed by rapid knockdown and mortality. Pyrethroids delivered a level of effectiveness against $B$. germanica not available before, and when combined with crack and crevice application, they set a new standard for cockroach control.

Accompanying the introduction of pyrethroids for cockroach control were dire predictions of resistance and widespread control failure if these compounds were extensively used (Cochran 1989; 1990). There was no data to justify these predictions, and they were not fulfilled. Pyrethroid resistance did develop in some field populations (Zhai and Robinson 1991), but it was not widespread, nor stable when exposure was removed (Zhai and Robinson 1996; Strong et al. 1997). The strategies proposed to prevent or manage pyrethroid resistance also lacked supporting data, as well as any practicality for pest control professionals. B. germanica has demonstrated the genetic capacity to develop resistance to nearly every modern insecticide used for its control, and it may retain moderate to high levels of resistance for many years, even in the absence of exposure (Bloomquist and Robinson 1999).

The most important contribution made by the pyrethroids to cockroach control was the sense that immediate and long-term control was achievable, and elimination of this pest was a possibility. Professional pest control operators realized that residential and commercial infestations could be significantly reduced by a single application, and subsequent applications provided further reduction. In the first few minutes of a pyrethroid application there was usually flushing of adults and nymphs from harborages, then cockroaches began to die. Organophosphates and carbamates are typically slow acting, with little flushing activity, and mortality occurs within days and not minutes. From this point on, cockroach control could be nothing less than odorless, fast acting, and with a flushing action.

\section{Baits}

The introduction of toxic baits for cockroach control was aided by the already established treatment strategies of identifying cockroach-infested harborages, and crack and crevice application. Add to this the characteristic of baits to provide knockdown and mortality within the first two to four days of feeding, and the increasing concern of the public for pesticides used indoors, and these materials were hailed as a major step forward in cockroach control. Baits as ready-to-use products were first widely used by homemakers, later they were adopted by the professional pest control industry. Within about ten years of their introduction baits have changed the pest status of the German cockroach, and the future of controlling other cockroach pests. The use of baits by homemakers and professionals changed not only changed cockroach control, but the entire concept of household pest control.

The qualities of bait formulations and their unique active ingredients are worthy of discussion. Briefly, once a small amount is eaten, the cockroach is immobilized and mortality occurs within days. The most important feature of cockroach control baits is how they are able to suppress local infestations or entire populations of $B$. germanica in a relatively short time. The reasons are linked to what traditional liquid applications did not do, which was reach males, females with and without egg cases, and all stages 
of nymphs at one time. Baits placed in or near cockroach-infested harborages are fed on by all segments of the population, especially the nymphs and females. The effect of this broad level of feeding was to reduce numbers to very low levels in a short time. In a sense, baits were capable of pushing a population over a theoretical 'tipping point' by quickly eliminating the current and future generations. A population reduced to such low numbers, may not be able to completely recover and continues to decline. Few individuals and the continued presence of palatable baits can result in elimination. Reservoirs

From the time $B$. germanica was first carried onto trading ships sailing from south Asia to European ports, reservoir populations have sustained its journey to households around the world. The infestations established on ships and in storage warehouses were key to the movement of this tropical insect to temperate regions. The modern chain of reservoirs includes food warehouses and large distribution centers, grocery stores, restaurants, commercial transportation, and finally households. At some of these reservoir sites there may be only limited use of chemical controls, and cockroach populations exposed to spot treatments or sub-lethal doses can develop resistance. From these reservoirs cockroaches are carried to the other sites along the chain, and these recruits can initiate or sustain other infestations.

The breakup of the reservoir system by the use of liquid and bait insecticides started with the household and spread to other parts of the system. Baits were initially more popular with homemakers than pest control professionals, and their efficacy was first realized in household kitchens and bathrooms. Once adopted by professionals and used in commercial sites, the reservoir system collapsed. Anywhere control or elimination was achieved, the prospect was good that there would be no re-infestation from the usual reservoirs - and this was key to the sequence of decline of this pest. The German cockroach does not live outdoors in the urban environment, and is dependent on being transported between reservoirs and infested sites. Take away the reservoir network and the cockroach-free sites can remain that way.

\section{RESULTS OF THE DECLINE OF GERMAN COCKROACH POPULATIONS}

A declining presence of $B$. germanica in the urban environment should be welcomed aesthetically and medically, and in large part it is. However, along with the obvious benefits there are some detractions, and caveats for the future. First the benefits. Removing from the living space an insect that carried the social stigma of poor housekeeping and low socio-economic status was a valuable contribution by modern science. But after years of infestation, cockroach fecal residues and body fragments remain, and these will probably continue to contribute to respiratory asthma and other health problems for those exposed. The challenge of the next generation of pest control professionals is to remove the allergens and prevent re-infestation.

It is likely that years of regularly spraying baseboards and exposed surfaces for cockroaches also provided control of other pests, such as ants, silverfish, carpet beetles, and spiders. These non-target pests occurred in the same habitats and were probably affected by the insecticide residues. The introduction of cockroach baits changed this scenario. Baits targeted only cockroaches, and the decreased use of broad spectrum, residual sprays resulted in the secondary pests becoming more numerous. Ants may be the most obvious benefactor of the decrease in household applications of liquid insecticides. In many urban environments ants are the number one household and structural pest. Others that seem to be increasing with the decline of German cockroaches include, silverfish, and stored food pests (Rasmussen and Nielsen 1997; Landau et al. 1999).

\section{FUTURE OF PERI-DOMESTIC AND DOMESTIC PEST CONTROL}

The control and elimination achieved with the German cockroach will not likely be immediately available for other pest species. There are natural reservoir populations of ants, yellowjackets, subterranean termites and other (nonsocial) insects, such as oriental cockroaches (Thoms and Robinson 1986; Le Patourel 1993) and American 
cockroaches (Bao and Robinson 1998) that will prevent this. This may be the most important feature of household and structural pest control in the future. There are both practical and philosophical aspects of the concept of eliminating insects from the urban environment by killing colonies and not simply preventing or reducing the human/insect interaction. Of course, the mere utility of removing subterranean termites or ants from urban environments does not mean that it is possible or economically feasible. The concept of a pest free perimeter around the house may be desirable, but at what cost in terms of pesticide load to peri-domestic habitats. This may be the ultimate value of baits: to deliver a high level of pest control with limited pesticide use.

\section{REFERENCES}

Bao, N. and Robinson, W., 1998. Sewers are superhighways for American cockroaches. Pest Control 66 (7): 30-33.

Bloomquist, J.R. and Robinson, W.H., 1999. Prevalence and magnitude of resistance to cyclodiene and phenylpyrazole insecticides in Blattella germanica and Drosophila melanogaster. In: Proceedings $3^{\text {rd }}$ Inter. Conference on Urban Pests, Prague, Czech Republic. W. Robinson and G. Rambo (Eds).

Cochran, D.G., 1989. Monitoring for insecticide resistance in field-collected strains of the German cockroach (Dictyoptera: Blattellidae). J. Econ. Entomol. 82: 336-341.

Cochran, D.G., 1990. Managing resistance in the German cockroach. Pest Control Technology 18 (2): 56-57.

Cole, M.M., LaBrecque, G.C. and Burden, G.S., 1959. Effects of gamma radiation on some insects affecting man. J. Econ. Entomol. 52: 448-450.

Farmer, B.R. and Robinson, W., 1984. Harborage limitation as a component of a German cockroach pest management program (Dictyoptera: Blattellidae). Proc. Entomol. Soc. Wash. 86: 269-273.

Koehler, P.G., Strong, C.A. and Patterson, R.S., 1994. Harborage width preferences of German cockroach (Dictyoptera: Blattellidae) adults and nymphs. J. Econ. Entomol. 87: 699-704.

Le Patourel, G.N., 1993. Environmental aspects of the survival and reproduction of oriental cockroaches (Blatta orientalis L.). In: Proceedings $1^{\text {st }}$ Inter. Conference on Insects in the Urban Environment, Cambridge, United Kingdom, K.B. Wildey and W. Robinson (Eds).

Landau, I., Muller, C. and Schmidt, M., 1999. The Urban Pest Advisory Service of Zurich (Switzerland) and the situation of some selected pests. In: Proceedings $3^{\text {rd }}$ Inter. Conference on Urban Pests, Prague, Czech Republic. W. Robinson and G. Rambo, (Eds).

Rasmussen, A.-M. and Nielsen, P.S., 1997. Some of the cases and characteristic variations in number of inquiries in 1997. Danish Pest Information Laboratory Annual Report 1997: 48-49.

Runstrom, E.S. and Bennett, G.W., 1984. Movement of German cockroaches as influenced by structural features of low-income apartments.J. Econ. Entomol. 77: 407-411.

Rust, M.K. and Reierson, D., 1991. Chlorpyrifos resistance inn German cockroaches (Dictyoptera: Blattellidae) from restaurants. J. Econ. Entomol. 84: 736-740.

Stejskal, V. and Verner, P.H., 1996. Long-term changes of cockroach infestations in Czech and Slovak food-processing plants. Medical and Veterinary Entomol. 10: 103-104.

Strong, C.A., Koehler, P.G. and Patterson, R.S., 1997. Insecticide resistance decline and selection in laboratory-reared German cockroaches (Dictyoptera: Blattellidae). J. Econ. Entomol. 90: 183-187.

Thoms, E.M. and Robinson, W.H., 1986. Distribution, seasonal abundance, and pest status of the oriental cockroach (Orthoptera: Blattidae) and a evaniid wasp (Hymenoptera: Evaniidae) in urban apartments. J. Econ. Entomol. 79: 431-436.

US Department of Agriculture Office of Governmental and Public Affairs, 1989. USDA keeping tabs on cockroaches. 17 October 1989, 1 page. 
Zhai, J., 1990. Habitat preference of cockroaches in urban environments in Shanghai, China. Jpn. J. Sanit. Zool. 41: 353-357.

Zhai, J. and Robinson, W.H., 1991. Pyrethroid resistance in a field population of German cockroach, Blattella germanica (L.). Jpn. J. Sanit. Zool. 42: 241-244.

Zhai, J. and Robinson, W.H., 1996. Instability of cypermethrin resistance in a field population of the German cockroach (Orthoptera: Blattellidae). J. Econ. Entomol. 89: 332-336.

Zungoli, P.A., 1982. Aspects of dispersal and population structure of Blattella germanica (L.) in field habitats and attitudes concerning aesthetic injury levels. Ph.D. Dissertation, Virginia Polytechnic Institute and State University, Blacksburg, VA, $100 \mathrm{pp}$. 